\title{
Comparing the effectiveness of mobile social network-based mindfulness intervention with acceptance and commitment therapy and mindfulness therapy on self-management and glycated haemoglobin level among patients with type 2 diabetes
}

\author{
Mohammad Mahdi Azadi ${ }^{\mathbb{D}}$, Gholamreza Manshaee $^{2 *}{ }^{\mathbb{D}}$, Mohsen Golparvar $^{3}$ \\ ${ }^{1}$ Ph.D. student of Psychology, Faculty of Psychology and Educational Sciences, Islamic Azad University, Isfahan (Khorasgan) \\ Branch, , Isfahan, Iran. \\ ${ }^{2}$ Associate Professor, Department of Psychology, Faculty of Psychology and Educational Sciences, Islamic Azad University, \\ Isfahan (Khorasgan)Branch, Isfahan, Iran. \\ ${ }^{3}$ Associate Professor, Department of Psychology, Faculty of Psychology and Educational Sciences, Islamic Azad University, \\ Isfahan (Khorasgan)Branch, Isfahan, Iran.
}

*Corresponding Author: Gholamreza Manshaee, Tel:+983135354042, Email: smanshaee@yahoo.com

\begin{abstract}
Background and aims: The present study aimed to compare mobile social network-based mindfulness training, along with acceptance and commitment therapy (ACT) and mindfulness therapy on self-management and glycated haemoglobin (HbA1c) level in patients with type 2 diabetes.

Materials and Methods: The research employed a pretest-posttest control group quasi-experimental design with a three-month follow-up. Among type 2 diabetic patients who referred to diabetes treatment centers in Isfahan in the spring of 2018, 80 of them were purposefully selected based on inclusion criteria and then randomly assigned to three groups of the social network-based mindfulness intervention, $\mathrm{ACT}$, and mindfulness training, along with a control group. Then, the summaries of Diabetes Self-care Activities questionnaire and glycated haemoglobin test were used to measure the dependent variables. The mindfulness interventions were conducted in the form of attendance in the training sessions. In addition, virtual network-based training and ACT were presented during eight 45-minute and 120-minute sessions, respectively. Finally, the data were analyzed using repeated measures of ANOVA with Bonferroni post-hoc test by SPSS software. Results: The findings indicated that in the self-management variable, there was a significant difference between social network-based mindfulness (posttest mean=30.59, follow-up mean=30.88, $P=0.004$ ) and ACT (posttest mean=32.7, follow-up mean=32.29, $P=0.001$ ) with the control group. Further, a significant difference was observed between ACT and mindfulness therapy regarding self-management $(P=0.04)$. In the HbA1c level, there was a significant difference only between social network-based mindfulness (mean in posttest and follow-up=7.44and 7.39, respectively, $P=0.02$ ) and the control group.

Conclusion: According to the findings of the present study, mobile social networks-based mindfulness interventions, along with ACT, are considered as effective treatments for diabetic patients to increase self-management while reducingHbA1c.

Keywords: Self-management, Glycated haemoglobin, Diabetes, Social network-based mindfulness, Acceptance and commitment therapy
\end{abstract}

Received: 31 January 2019, Accepted: 27 April 2019, ePublished: 30 October 2019

Introduction

Type 2 diabetes mellitus is an increasingly common chronic disease afflicting 171 million individuals in 2000. Based on the estimations, this number reaches 366 million people by 2030 (1). Diabetes is a chronic illness that places a significant self-management burden on affected individuals and families. In this regard, health behaviors such as medication adherence, diet, physical activity, and blood glucose self-monitoring are important for achieving optimal glycemic control in diabetes (2). Self-management is considered as one of the most important variables in controlling diseases, which is a set of learned, conscious, and purposeful behaviors performed by a patient and his/ her family in accordance with the objective situations of life. In fact, this is the patient who can select from among the clinical options offered by the healthcare team with respect to the context and culture of his/her life and control his/her illness most appropriately (3). In addition,

(C) 2019 The Author(s); Published by Shahrekord University of Medical Sciences. This is an open-access article distributed under the terms of the Creative Commons Attribution License (http://creativecommons.org/licenses/by/4.0), which permits unrestricted use, distribution, and reproduction in any medium, provided the original work is properly cited. 
diabetes treatment generally involves self-management behaviors including daily insulin injections, drug use, glucose control, physical activity, and dietary habits (4). Proper self-management is associated with a low level of A1c, reflecting a possible $37 \%$ reduction in diabetes-related complications (5). The aim of the treatment is to create a level of glycosylated hemoglobin (HbA1c) that is as close to the normal level as possible and does not expose the patient to hypoglycemia (6).

HbA1c test is a very common blood test which is effective in screening diabetics and shows how well patients are successful in controlling the diabetes (7). The HbA1c or long-term glucose, which determines the amount of glucose within 8 to 12 weeks, is a standard for long-term blood glucose control (8). Further, self-management is an active and practical process which is directed by the patient and includes specific activities for achieving the goals of managing the disease (9). Similarly, self-management as an appropriate lifestyle intervention for patients with type 2 diabetes is successful in helping patients reduce fat intake, increase physical activity, and decrease obesity (10). Chew et al emphasize that the effective management of diabetes by the treatment team and the community requires the psychology and knowledge of the relationship between encouragement and hope with the pursuit of health-related behaviors (11).

Many studies offer good research protocols for the mindfulness interventions of diabetes mellitus, which seem to have a positive effect on all aspects of diabetes including its occurrence, control, and complications. The efficacy of acceptance and commitment therapy (ACT) has been observed in many psychological problems as to the quality of the life of patients with type 2 diabetes (12), but the need for regular practice is regarded as one of the main limitations of mindfulness and ACT interventions. In the past few years, one of the improvements in diabetes care is the widespread contribution of e-society in which people share practical experiences and mutual support for self-help (13). Moreover, internet interventions for the management of type 2 diabetes have led to increased social support (14), increased self-efficacy (15), improved glycemic control (16), and self-managed behaviors (17), as well as reduced number of visits to hospitals and emergency rooms (18).

The best diabetes self-management training programs on the Internet provide the concepts and content of diabetes disease, engagement, personal learning experiences, and self-assessment tools for monitoring and providing feedback (19). Likewise, Internet interventions such as virtual environments provide access to concurrent and indirect diabetes education, along with skill-building and peer-topeer support activities. Vorderstrasse et al highlighted the impact of diabetes self-management education as the first step in this area and hoped to use an alternative internetbased model for teaching diabetes self-management (20).

Considering that various psychological treatments are used for diabetes, this is the first time that, to the best of our knowledge, the psychological intervention of mindconsciousness is based on the mobile social network for diabetes. The present study sought to compare the effectiveness of mobile social network-based mindfulness intervention with ACT and mindfulness therapy on selfmanagement and HbA1c level among patients with type 2 diabetes.

\section{Materials and Methods}

In the first step, considering the validity of the content of the mobile social network-based mindfulness interventions, the research was of survey type and specialized validation. In the second step, the type of research was semi-experimental and the research design was a pre-test, post-test with a control group and a follow-up period of three months.

The statistical research population consisted of two groups. The first group included experts in the field of cognitive-behavioral learning and mindfulness education in Isfahan, who determined the validity of the package of mobile social network-based mindfulness interventions. Additionally, the second group encompassed patients with type 2 diabetes who referred to Dr. Gharazi and Dr. Shariati hospitals in Isfahan during spring 2018.

The research sample contained two groups including six knowledgeable specialists in mindfulness training who were randomly sampled in the first group and diabetic patients who referred to diabetes clinics of Gharazi and Shariati hospitals in Isfahan. Their number was about 3500 at the time of the study. Based on the inclusion criteria, 80 people were intentionally selected and then randomly assigned to experimental and control groups. This sample number was recommended by approximately 15 people for experimental studies and by considering a possible dropout rate in the time of research execution (21). The referrals were obtained and presented to Gharazi and Shariati hospitals for the presence of a researcher for collecting data, as well as for conducting a purposive sampling of patients with diabetes by taking the necessary measures. Next, the patients were selected through the installation of calls and invitations in the diabetes clinic of the hospitals and evaluated based on the inclusion and exclusion criteria, as well as their full awareness (obtaining informed consent) with observance to confidentiality and full respect for their health. To this end, the purposive random sampling technique was used based on the inclusion and exclusion criteria, in addition to taking into consideration the fully ethical and accepted procedures in scientific and academic references such as Tovote et al (22) and Kabat-Zinn (23).

The participants were randomly assigned (lottery) to the mobile social network-based mindfulness intervention experimental (MSNBMI), ACT, mindfulness intervention (MI), and control groups, each containing 20 participants.

The research inclusion criteria were suffering from type 2 diabetes mellitus according to the diagnosis of diabetes, 
having reading and writing skills, having medical records at the Diabetes Clinics of Dr. Gharazi and Shariati Superspecialty hospitals, having knowledge of working with mobile social networks, and having a glycated haemoglobin level of at least $7.5 \%$.

The exclusion criteria included being absent from interventions for more than two sessions, being dissatisfied with the continuation of the research, suffering from acute psychotic disorder based on clinical interviews, and receiving psychological therapy over the past three months.

According to the previous agreement with the group members, the experimental group of the mobile social network-based MIs all agreed to connect to the social network at 9 o'clock in the evening, which lasted 45 minutes a day except for holidays for 8 weeks. These interventions were performed using the mindfulness training package (23), and the file was sent to the patients as text, audio, image, video, and animation. Then, the feedback and answers like in-person meetings were received but via the Telegram social network (Table 1). This training package was also used in the study by van Son et al for investigating the effectiveness of reducing anxiety in patients with diabetes (24). The repeated measurement analysis process is presented in Figure 1.

It should be noted that the treatment package (Table 1) was performed for the second experimental group in person.

As shown in Table 2, the ACT experimental group (20 participants) received eight 120-minute ACT sessions using the ACT training program (25). This training package was developed by Gregg and Hayes (2004) and used by Gregg et al (5) and Gregg (25) for diabetic patients.

\section{Research Instruments}

1. The HbA1c test: A blood sample that the laboratory takes from a person to examine his diabetes status. HbA1c shows the amount of glucose within 2 to 3 months before sampling. If blood glucose levels are higher than normal over the past few weeks (100), HbA1c levels will also be high (5).

The summary of diabetes self-care activities measure: This scale, designed by Toobert et al, records the self-care activities of diabetes. It contains 11 items for assessing diabetes selfcare in five dietary areas (questions 1-4), physical activity (questions 5 and 6), blood glucose monitoring (questions 7 and 8), foot care (questions 9 and 10), and smoking (question 11) during the last week. This instrument employs an 8-point Likert-type scale ranging from 0 to 7. For questions 1 to 10 , the numerical average (from 0 to 7 ) means the number of days that a patient has completed the required self-care activity and taken the appropriate score. For question 11 , a score of 0 or 1 is given to the patient in

Table 1. A summary of mindfulness-based interventions

\begin{tabular}{|c|c|}
\hline Sessions & Contents \\
\hline 1 & $\begin{array}{l}\text { 1. Providing information on the mindfulness training and its definition, as well as an explanation regarding the reasons for the } \\
\text { implementation of this training course for the participants. In addition, explaining how to plan for mindfulness exercises and incorporate } \\
\text { these exercises into daily life, presenting daily notes about the mindfulness exercises, along with training and doing mindfulness } \\
\text { exercises (how to sit on a chair, lying position, sitting in a cross-legged position, complete lotus mode, and hand position); } \\
\text { 2. Exercising attention to breathing. This exercise involves attention to breathing, and participants should not try to control their breathing } \\
\text { behaviors. The mindful breath is considered as the awareness of each inhalation and exhalation }\end{array}$ \\
\hline 2 & $\begin{array}{l}\text { 1. Doing mindfulness exercises; } \\
\text { 2. Doing body scan mindfulness exercise. This exercise takes about } 45 \text { minutes and is one of the formal mindfulness exercises. In this } \\
\text { exercise, the participants are placed in a sleep state and pay attention to each body area with a special order. This exercise increases } \\
\text { concentration and flexibility of attention in addition to focusing on the present moment }\end{array}$ \\
\hline 3 & $\begin{array}{l}\text { 1. Practising meditation in a sitting position. In this exercise, a sitting position can be performed on the chair or floor and a cushion. In this } \\
\text { type of meditation, it is advisable to have a perfectly smooth spine so that consciousness is at its highest level. Furthermore, attention is } \\
\text { paid to breathing, each inhalation and exhalation and following it instantaneously. This exercise takes about } 30 \text { minutes; } \\
\text { 2. Paying attention to breathing practice involves several options including sitting with breathing, as well as sitting with breathing and body } \\
\text { as a whole. Exercising with sounds (in this exercise hearing the sounds without judgment about them), exercising sitting with thoughts } \\
\text { and feelings (observing thoughts and feelings as they are) }\end{array}$ \\
\hline 4 & $\begin{array}{l}\text { Doing mindful exercises (yoga) that increase balance and flexibility. Mindful Hatha yoga is one of the formal mindful exercises which involves } \\
\text { slow stretching, along with momentary breathing and physical sensations which are created during the exercise }\end{array}$ \\
\hline 5 & Doing the exercise of eating a raisin mindfully to raise the awareness of the moment of being and get out of the auto-guidance mode \\
\hline 6 & Doing mediation of mindful walking (Being aware of any walking moment) \\
\hline 7 & $\begin{array}{l}\text { 1. Reviewing and rehearsing the exercises of the previous sessions and discussing the present moment; } \\
\text { 2. Explaining the formal and informal mindful exercises }\end{array}$ \\
\hline 8 & $\begin{array}{l}\text { At this stage, according to the Kabat-Zein program, participants are allowed to evaluate the exercises they have done so far and select the } \\
\text { exercises that are appropriate for themselves. In fact, the program provides their personal mindfulness whether they want to do formal or } \\
\text { informal exercises or they want to practice using or not using guidance audio files. However, this session is the last one of the eight-week } \\
\text { mindfulness program and the first session of each individual exercise in his/her life }\end{array}$ \\
\hline
\end{tabular}




\begin{tabular}{|c|c|}
\hline Sessions & Contents \\
\hline 1 & $\begin{array}{l}\text {-Familiarity of the group members with each other, as well as the therapy and the introduction of its main axes; } \\
\text {-Illumination of the values of the patient-presentation of information about diabetes and its types }\end{array}$ \\
\hline 2 & $\begin{array}{l}\text { - Presentation of information on the level of balanced blood sugar and clinical signs of high and low blood sugar such as the care of the feet } \\
\text { and eyes; The patients' values are addressed from the first session and targeted at all sessions; } \\
\text { - Examination of the level of mental acceptance and rejection of patients; } \\
\text { - Survey of the level of social and family support; } \\
\text { - Use of the metaphors of ACT }\end{array}$ \\
\hline 3 & $\begin{array}{l}\text { The significance of food in diabetes management and good nutrition; } \\
\text { Diabetes management aims to reduce complications and body weight, keep blood glucose levels close to normal, and focus on the value and } \\
\text { choice of choice }\end{array}$ \\
\hline 4 & -Use of mindfulness techniques related to ACT \\
\hline 5 & $\begin{array}{l}\text {-Attention to exercises and diabetes and the significance of exercises in managing diabetes, which is the points that should be taken into } \\
\text { consideration before exercising }\end{array}$ \\
\hline 6 & $\begin{array}{l}\text {-Use of techniques to accept unwanted thoughts and feelings-design of a daily exercise plan; } \\
\text { - Implementation of diabetes mindfulness techniques }\end{array}$ \\
\hline 7 & $\begin{array}{l}\text {-Determination of a daily exercise plan; } \\
\text { - Implementation of mindfulness techniques for diabetes; } \\
\text {-Management of stress and coping }\end{array}$ \\
\hline 8 & $\begin{array}{l}\text {-Use of acceptance adherence regarding the disease, as well as related complications, thoughts, and feelings and the use of related } \\
\text { metaphors; } \\
\text { - Behavioral engagement exercises }\end{array}$ \\
\hline
\end{tabular}

Note. ACT: Acceptance and commitment therapy.

the case of not smoking or smoking, respectively. It should be noted that question 4 is inversely scored. Overall, the score shows the level of a patient's self-management (26). Toobert et al indicated that this questionnaire has high internal consistency and mentioned it as a valid indicator for self-management of diabetes (26). The coefficient of internal consistency reported by the scale maker in the English and Spanish editions was 0.82 and 0.85, respectively. In the study by Nikoogoftar and Eshaghi, its Cronbach alpha coefficient was 0.65 , while in the present study, its Cronbach alpha coefficient was 0.73 .

\section{Data Analysis}

The repeated measures of ANOVA were employed for data analysis. Before performing repeated measures of ANOVA, the normality presumption of variables, the homogeneity of error variance, and sphericity were investigated through the Shapiro-Wilk, Levene's, and Mauchly's tests, respectively. These analyses were performed using SPSS software, version 23. The minimum and maximum acceptable significance levels in the present study were 0.05 and 0.001 , respectively.

\section{Results}

In the social network-based MI group, 13 participants were female $(76.5 \%)$ and 4 ones were male $(23.5 \%)$. In the mindfulness therapy group, 12 participants were female $(80 \%)$ and 3 of them were male $(20 \%)$. As regards the ACT group, 11 participants were female $(64.7 \%)$ and 6 of them were male (35.3\%). Regarding the control group,
12 participants were female (75\%) and 4 ones were male (25\%). The results of the chi-square test showed that there was no significant difference between the four research groups in terms of age $\left(\chi^{2}=71.54, P=0.092\right)$, education $(\chi$ $\left.{ }^{2}=5.64, P=0.46\right)$, and gender $\left(\chi^{2}=1.101, P=0.78\right)$. The results of the Shapiro-Wilk test in the pre-test $(P=0.64$ $\& P=0.08)$, post-test $(P=0.07 \& P=0.06)$, and followup $(P=0.1 \& P=0.26)$ stages also indicated a normal distribution of self-care and glycosylated hemoglobin (HbA1c). Based on the results of Levene's test, the error variances were homogenous in the four groups regarding self-care $(P=0.35)$ and HbAlc $(P=0.75)$. In contrast, the results of Mauchly's sphericity test demonstrated the significance of the test for self-care and HbAlc $(P=0.001$ and $P=0.004$, respectively). This means that sphericity assumption was not met for the implementation of the repeated measures of ANOVA, and therefore, instead of referring to the default sphericity row in the result table of this type of analysis, it is necessary to consider the next row (i.e., the row related to the Greenhouse-Geisser test). Investigating the mean and standard deviation of selfmanagement variable in the four groups in the pre-test, post-test, and follow-up stages revealed that this variable was higher in the three experimental groups compared with the control group, while the HbA1c level was lower in the three experimental groups as compared to the control group (Table 3).

The results of repeated measures of ANOVA indicated that the test factor $(\mathrm{F}=53.83, \mathrm{df}=1.49, \quad P<0.01)$, the 
Table 3. The mean (SD) of self-management and $\mathrm{HbA1c}$ level in 4 groups in pre-test, post-test, and follow-up stages

\begin{tabular}{|c|c|c|c|c|c|}
\hline \multirow[t]{2}{*}{ Variable } & \multirow[t]{2}{*}{ Stage } & $\begin{array}{c}\text { Social Network-based } \\
\text { Mindfulness Interventions }\end{array}$ & $\mathrm{ACT}$ & Mindfulness & Control Group \\
\hline & & Mean (SD) & Mean (SD) & Mean (SD) & Mean (SD) \\
\hline \multirow{3}{*}{ Self-management } & Pre-test & $23.53(3.22)$ & $24.35(5.48)$ & $23.53(2.39)$ & $22.81(2.26)$ \\
\hline & Post-test & $30.59(6.32)$ & 32.7 (4.89) & $28.93(4.01)$ & $25.25(3.73)$ \\
\hline & Follow-up & $30.88(5.68)$ & $32.29(3.23)$ & $27.73(3.81)$ & $25.44(3.26)$ \\
\hline \multirow{3}{*}{$\mathrm{HbA1c}$} & Pre-test & $8.31(0.71)$ & $8.67(0.87)$ & $8.44(0.91)$ & $8.56(0.76)$ \\
\hline & Post-test & $7.44(0.66)$ & $7.52(0.79)$ & $7.87(0.74)$ & $8.48(1.1)$ \\
\hline & Follow-up & $7.39(0.71)$ & $7.41(0.66)$ & $7.87(0.56)$ & $8.45(1.07)$ \\
\hline
\end{tabular}

Note. HbA1c: glycosylated hemoglobin; ACT: acceptance and commitment therapy; SD: standard deviation.

\begin{tabular}{|c|c|c|c|c|c|}
\hline Variable and Test & Sum of Squares & Mean Square & $F$ value & $P$ value & Effect Size \\
\hline \multicolumn{6}{|c|}{ Self-management-Greenhouse-Geisser } \\
\hline Time* & 1392.49 & 933.25 & 53.83 & 0.001 & 0.47 \\
\hline Group** & 785.04 & 252.68 & 8.92 & 0.001 & 0.3 \\
\hline Time $^{*} \times$ Group $^{* *}$ & 219.71 & 49.08 & 2.83 & 0.01 & 0.12 \\
\hline \multicolumn{6}{|c|}{ HbA1c-Greenhouse-Geisser } \\
\hline Time $^{*}$ & 21.28 & 12.42 & 24.68 & 0.001 & 0.53 \\
\hline Group $^{* *}$ & 17.3 & 5.67 & 3.41 & 0.02 & 0.14 \\
\hline Time $^{*} \times$ Group $^{* *}$ & 7.22 & 1.4 & 7.72 & 0.001 & 0.27 \\
\hline
\end{tabular}

group factor $(\mathrm{F}=8.98, \mathrm{df}=3, P<0.01)$, and the interaction of the test and the group $(\mathrm{F}=2.83=2, \mathrm{df}=1.48, P<0.01)$ were significant respecting self-management. These results represent that there was a significant difference at least between two out of four groups regarding self-management in the post-test and follow-up stages. As regards the HbA1c level, the test factor $(\mathrm{F}=24.68, \mathrm{df}=1.71, P<0.01)$, group factor $(\mathrm{F}=3.41, \mathrm{df}=3, P<0.01)$, and the interaction of the test and group $(\mathrm{F}=7.72, \mathrm{df}=5.14, P<0.01)$ were significant as well. Based on the results, a significant difference was observed between at least two out of four groups with regard to the HbAlc level in the post-test and follow-up stages (Table 4).

Similarly, the Bonferroni post-hoc test was employed to determine the difference between each two groups. The results of the Bonferroni post hoc test regarding the selfmanagement variable showed that there was a significant difference between the social network-based mindfulness intervention and the control group $(P=0.004)$, as well as between the ACT group with mindfulness therapy $(P=0.04)$ and the control group $(P=0.001)$. However, no significant difference was found between the social networkbased mindfulness intervention with ACT $(P>0.99)$ and mindfulness therapy $(P=0.88)$, as well as between the mindfulness therapy and the control group $(P=0.28)$. Contrarily, there was a significant difference between the social network-based mindfulness intervention and the control group $(P=0.02)$ in terms of the HbA1c level. However, the results demonstrated no significant difference between the mindfulness therapy group $(P=0.72)$ and the ACT group $(P=0.11)$, as well as between the control and mindfulness therapy groups and the ACT group $(P>0.99)$.
Moreover, no significant difference was observed between the social network-based mindfulness intervention and the mindfulness therapy and ACT groups $(P>0.99)$; the details of which are provided in Table 5.

\section{Discussion}

The aim of the present study was to investigate the effectiveness of the social network-based mindfulness interventions with group ACT and group mindfulness intervention on self-management and HbA1c level in patients with type 2 diabetes. Based on the results, there was a significant difference between the effectiveness of the social network-based mindfulness interventions, group ACT, and mindfulness therapy on the self-management of patients with type 2 diabetes. As regards self-care, a significant difference was also found between the social network-based mindfulness therapy group and the control group, as well as between the ACT group and mindfulness therapy group. There was a significant difference between the ACT group and the control group in terms of self-care as well.

Moreover, a significant difference was observed between the social network-based mindfulness therapy group and the control group, but there was no significant difference between the social network-based mindfulness therapy group and the ACT and mindfulness therapy groups. Therefore, there was only a significant difference between the social network-based mindfulness therapy group and the control group in terms of the HbAlc level. These results are consistent with part of the findings of Nikodfatar and Ishaqi (27), in the study about the effectiveness of mindfulness training on self-care in women with type 
Table 5. Bonferroni test results for the pair comparison of research groups regarding self-management and HbA1c

\begin{tabular}{|c|c|c|c|c|}
\hline I Group & J Group & I-J Group & SE & $P$ value \\
\hline \multicolumn{5}{|l|}{ Self-management } \\
\hline Social network-based mindfulness intervention & $\mathrm{ACT}$ & -1.45 & 1.05 & $>0.99$ \\
\hline Social network-based mindfulness intervention & Mindfulness therapy & 1.6 & 1.09 & 0.88 \\
\hline Social network-based mindfulness intervention & Control group & 3.83 & 1.07 & 0.004 \\
\hline $\mathrm{ACT}$ & Mindfulness therapy & 3.05 & 1.09 & 0.04 \\
\hline ACT & Control group & 5.28 & 1.07 & 0.001 \\
\hline Mindfulness therapy & Control group & 2.23 & 1.1 & 0.28 \\
\hline \multicolumn{5}{|l|}{$\mathrm{HbA1c}$} \\
\hline Social network-based mindfulness intervention & $\mathrm{ACT}$ & -0.16 & 0.25 & $>0.99$ \\
\hline Social network-based mindfulness intervention & Mindfulness therapy & -0.36 & 0.26 & $>0.99$ \\
\hline Social network-based mindfulness intervention & Control group & -0.78 & 0.26 & 0.02 \\
\hline ACT & Mindfulness therapy & -0.2 & $0 / 26$ & $>0.99$ \\
\hline ACT & Control group & -0.6 & 0.26 & 0.11 \\
\hline Mindfulness therapy & Control group & -0.42 & 0.27 & 0.72 \\
\hline
\end{tabular}

Note. I Group: Social network-based mindfulness intervention, ACT: Mindfulness therapy; SE; Standard error; J Group; ACT, Mindfulness therapy, Control Group; HbA1c:Glycosylated hemoglobin; ACT: Acceptance and commitment therapy.

2 diabetes. Likewise, the results of the present study are in line with those of the studies by Zare et al (28) that evaluated the effectiveness of mindfulness in reducing stress in patients with diabetes, as well as Rosenzweig et al (29) that investigated the effectiveness of mindfulness-based intervention on physiology in improving blood glucose regulation in patients with diabetes.

Considering these results, it can be concluded that ACT has six core processes including contacting the present moment, defusion, acceptance, self-as-context, values, and the committed action (30), and the main goal is to create psychosocial flexibility and increase the ability of patients with diabetes to respond effectively to thoughts and feelings. Thus ACT is effective in the self-management of diabetic patients. Furthermore, mindfulness needs to grow three qualities of refraining from judgment, purposeful awareness, and focus on the present moment in the individual's attention, and concentration on the present moment results in processing all immediate empirical aspects including cognitive, physiological, or behavioral activities. By mindfulness-based exercises and techniques, one becomes aware of his/her daily activities and recognizes the automatic functioning of the mind in the past and future worlds. In addition, through moment to moment awareness of thoughts, emotions, and physical states, one controls them and abandons the daily and automated minds focused on the past and future (Rygh\& Sanderson, 2004). In this regard, social network-based mindfulness therapy has the benefits of virtual education as follows:

- The ability to store abundant information;

- The lack of anxiousness during training;

- The addition of new information to previous content;

- Access to information at any time;

- Use of practices with different colors, motions, and scenes, along with sounds and images which make learners' training more inclusive (31).
Virtual networks play an important role in the overall impact of participation in diabetes care around the world to care for the health of diabetic patients. The active participation of the healthcare receiver and provider is a key aspect of the successful management of chronic diseases. This is especially important in managing diabetes, where many key activities are in the hands of the patient (32). The effectiveness of mobile apps in the spirit of technology has been confirmed as a complementary tool in many psychotherapies (33). For instance, such apps can increase the independence of people with diabetes, increase self-management, make daily activities easier, increase their health states, enrich medical knowledge, make communication between sufferers be done more appropriately, and ultimately, increase their quality of life (34). In addition, in a meta-analysis conducted on the effectiveness of Internet-based mindfulness interventions, it was confirmed that this approach has the potential to help improve the mental health outcomes, especially stress (35). Parsons et al investigated 43 studies on mindfulness interventions and found that participants did averagely $64 \%$ of home exercises, and thus indicated that this average can be increased by using the online system and daily pursuits (36). In explaining the findings of the research, it can be concluded that emotional and psychological support increases in day-to-day sessions under the social network and the formation of the group. According to previous studies, patients in weekly sessions only make up about $64 \%$ of the exercises and recommendations, and therefore, daily exercises and recommendations are enhanced and followed up in daily sessions and will be tracked throughout the week. It seems that daily care increases the physical and mental activities that are associated with self-management behaviors of the patients and thus leads to more effectiveness in the social network-based mindfulness intervention. Further, depression is one of the complications associated with diabetes, which is observed 
in most diabetic patients and daily sessions prepare them for physical and psychological activity. In contrast, patients with depression do not have the required energy to perform exercises and recommendations in weekly sessions, which can lead to differences in the obtained results regarding the effectiveness of the groups.

\section{Conclusion}

Based on the findings of the current research, the mobile social network-based mindfulness interventions, along with ACT, are regarded as effective treatments for diabetic patients in order to increase self-management while reducing HbA1c. Therefore, medical centers and diabetes clinics are recommended to increase the level of selfmanagement and reduce the level of HbA1cby launching the mobile social network-based mindfulness training and ACT.

\section{Conflicts of interests}

None.

\section{Ethical considerations}

The present research was extracted from the Ph.D. dissertation of psychology and approved by the Ethics Committee of Islamic Azad University of Isfahan (Khorasgan) under the ethical code of IR.IAU. KHUISF.REC.1397.22.

\section{Acknowledgments}

This article was extracted from a Ph.D. dissertation in Psychology under the code number 23820705952095 submitted at the Islamic Azad University of Isfahan (Khorasgan). We are obliged to be grateful to all the respectable patients who collaborated in this research, as well as to the sincere work of Mrs. Laleh Hosseini who was involved in training the mindfulness intervention.

\section{References}

1. van Dooren FE, Denollet J, Verhey FR, Stehouwer CD, Sep SJ, Henry RM, et al. Psychological and personality factors in type 2 diabetes mellitus, presenting the rationale and exploratory results from The Maastricht Study, a population-based cohort study. BMC Psychiatry. 2016;16:17. doi: 10.1186/s12888-0160722-z.

2. Gonzalez JS, Tanenbaum ML, Commissariat PV. Psychosocial factors in medication adherence and diabetes self-management: Implications for research and practice. Am Psychol. 2016;71 (7):539-51. doi: 10.1037/a0040388.

3. Hemati Z, Mosaviasl FS, Abasi S, Ghazavi Z, Kiani D. Effect of Orem's self-care model on self-esteem of adolescents with asthma referred to an asthma and allergy clinic in Isfahan. Tanaffos. 2015;14 (4):232-7.

4. Clark M, Asimakopoulou KG. Diabetes in older adults. In: Snoek FJ, Skinner TC, ed. Psychology in diabetes care. 2nd ed. West Sussex: John Wiley \& Sons, Ltd; 2005. p. 61-93.

5. Gregg JA, Callaghan GM, Hayes SC, Glenn-Lawson JL. Improving diabetes self-management through acceptance, mindfulness, and values: a randomized controlled trial. J Consult Clin Psychol. 2007;75 (2):336-43. doi: 10.1037/0022006x.75.2.336.

6. Kasper DL, Braunwald E, Fauci AS, Hauser SL, Longo DL, Jameson JL. Harrison's Principles of Internal Medicine. 16th ed. McGraw Hill; 2005. p. 329-36.
7. Cobden DS, Niessen LW, Barr CE, Rutten FF, Redekop WK. Relationships among self-management, patient perceptions of care, and health economic outcomes for decision-making and clinical practice in type 2 diabetes. Value Health. 2010;13 (1):138-47. doi: 10.1111/j.1524-4733.2009.00587.x.

8. Thorpe CT, Fahey LE, Johnson H, Deshpande M, Thorpe JM, Fisher EB. Facilitating healthy coping in patients with diabetes: a systematic review. Diabetes Educ. 2013;39 (1):33-52. doi: 10.1177/0145721712464400.

9. Holman $\mathrm{H}$, Lorig K. Patient self-management: a key to effectiveness and efficiency in care of chronic disease. Public Health Rep. 2004;119 (3):239-43. doi: 10.1016/j. phr.2004.04.002.

10. Clark M, Hampson SE, Avery L, Simpson R. Effects of a tailored lifestyle self-management intervention in patients with type 2 diabetes. Br J Health Psychol. 2004;9 (Pt 3):365-79. doi: 10.1348/1359107041557066.

11. Chew BH, Shariff-Ghazali S, Fernandez A. Psychological aspects of diabetes care: effecting behavioral change in patients. World J Diabetes. 2014;5 (6):796-808. doi: 10.4239/ wjd.v5.i6.796.

12. FathiAhmadsaraei N, NeshatDoost HT, Manshaee GR, Nadi MA. The effectiveness of acceptance and commitment therapy on quality of life among patients with type 2 diabetes. Iranian Journal of Health Education and Health Promotion. 2016;4 (1):31-9. doi: 10.18869/acadpub.ihepsaj.4.1.31. [Persian].

13. Toh SH, Lee SC, Chung WY. WSN based personal mobile physiological monitoring and management system for chronic disease. In Convergence and Hybrid Information Technology, 2008. ICCIT'08. Third International Conference on 2008 Nov 11 (Vol. 1. IEEE; 2008. p. 476-2.

14. Resnick PJ, Janney AW, Buis LR, Richardson CR. Adding an online community to an internet-mediated walking program. Part 2: strategies for encouraging community participation. J Med Internet Res. 2010;12 (4):e72. doi: 10.2196/jmir.1339.

15. Glasgow RE, Kurz D, King D, Dickman JM, Faber AJ, Halterman $\mathrm{E}$, et al. Twelve-month outcomes of an Internet-based diabetes self-management support program. Patient Educ Couns. 2012;87 (1):81-92. doi: 10.1016/j.pec.2011.07.024.

16. Lorig K, Ritter PL, Laurent DD, Plant K, Green M, Jernigan VB, et al. Online diabetes self-management program: a randomized study. Diabetes Care. 2010;33 (6):1275-81. doi: 10.2337/ dc09-2153.

17. Lorig K. Patient-centered care: depends on the point of view. Health Educ Behav. 2012;39 (5):523-5. doi: $10.1177 / 1090198112455175$.

18. Welch G, Shayne R. Interactive behavioral technologies and diabetes self-management support: recent research findings from clinical trials. Curr Diab Rep. 2006;6 (2):130-6.

19. Ramadas A, Quek KF, Chan CK, Oldenburg B. Web-based interventions for the management of type 2 diabetes mellitus: a systematic review of recent evidence. Int J Med Inform. 2011;80 (6):389-405. doi: 10.1016/j.ijmedinf.2011.02.002.

20. Vorderstrasse AA, Melkus GD, Pan W, Lewinski AA, Johnson CM. Diabetes Learning in Virtual Environments: Testing the Efficacy of Self-Management Training and Support in Virtual Environments (Randomized Controlled Trial Protocol). Nurs Res. 2015;64 (6):485-93. doi: 10.1097/nnr.0000000000000128.

21. Sarmad Z, Bazargan A, Hejazi E. Research Methods in Behavioral Sciences. Tehran: Agah Publications; 2012. p. 1327 .

22. Tovote KA, Fleer J, Snippe E, Bas IV, Links TP, Emmelkamp PM, et al. Cognitive behavioral therapy and mindfulnessbased cognitive therapy for depressive symptoms in patients with diabetes: design of a randomized controlled trial. BMC 
Psychol. 2013;1 (1):17. doi: 10.1186/2050-7283-1-17.

23. Kabat-Zinn J. Full Catastrophe Living: Using the Wisdom of Your Body and Mind to Face Stress, Pain and Illness. New York: Dell Publishing; 1990.

24. van Son J, Nyklícek I, Pop VJ, Blonk MC, Erdtsieck RJ, Spooren $P F$, et al. The effects of a mindfulness-based intervention on emotional distress, quality of life, and $\mathrm{HbA}(1 \mathrm{c})$ in outpatients with diabetes (DiaMind): a randomized controlled trial. Diabetes Care. 2013;36 (4):823-30. doi: 10.2337/dc12-1477.

25. Gregg JA. A randomized controlled effectiveness trial comparing patient education with and without acceptance and commitment therapy for type 2 diabetes self-management [dissertation]. Reno: University of Nevada; 2004.

26. Toobert DJ, Hampson SE, Glasgow RE. The summary of diabetes self-care activities measure: results from 7 studies and a revised scale. Diabetes Care. 2000;23 (7):943-50. doi: 10.2337/diacare.23.7.943.

27. Nikodfatar M, Ishaqi F. Prediction of Self-care Behaviors of Patients with Diabetes Based on Attachment Styles and Health Control Center: Moderating Role of Gender. Quarterly Journal of Health Psychology. 2013;1 (4):84-96. [Persian].

28. Zare H, Zare M, khalegi Delavar F, Amirabadi F, Shahriari $\mathrm{H}$. Mindfulness and diabetes: evaluation of effectiveness of Mindfulness Based Stress Reductionon glycemic control in diabetes. Razi Journal of Medical Sciences. 2013;20 (108):4052. [Persian].

29. Rosenzweig S, Reibel DK, Greeson JM, Edman JS, Jasser SA, McMearty KD, et al. Mindfulness-based stress reduction is associated with improved glycemic control in type 2 diabetes mellitus: a pilot study. Altern Ther Health Med. 2007;13 (5):368.
30. Prevedini AB, Presti G, Rabitti E, Miselli G, Moderato P. Acceptance and commitment therapy (ACT): the foundation of the therapeutic model and an overview of its contribution to the treatment of patients with chronic physical diseases. G Ital Med Lav Ergon. 2011;33 (1 Suppl A):A53-63.

31. Maindal HT, Bonde A, Aagaard-Hansen J. Action research led to a feasible lifestyle intervention in general practice for people with prediabetes. Prim Care Diabetes. 2014;8 (1):23-9. doi: 10.1016/j.pcd.2013.11.007.

32. Warren J, Lundstrom $M$, Osborne $D$, Kempster $M$, Jones S, Ma C, et al. A multi-interface, multi-profiling system for chronic disease management learning. In Proceedings of the 37th Annual Hawaii International Conference on System Sciences, 2004. (pp. 10-pp). IEEE; 2004. doi: 10.1109/ HICSS.2004.1265392.

33. 33. Miller G. The smartphone psychology manifesto. Perspect Psychol Sci. 2012;7 (3):221-37. doi: $10.1177 / 1745691612441215$.

34. Chorbev I, Sotirovska M, Mihajlov D. Virtual communities for diabetes chronic disease healthcare. Int J Telemed Appl. 2011;2011:721654. doi: 10.1155/2011/721654.

35. Spijkerman MP, Pots WT, Bohlmeijer ET. Effectiveness of online mindfulness-based interventions in improving mental health: a review and meta-analysis of randomised controlled trials. Clin Psychol Rev. 2016;45:102-14. doi: 10.1016/j.cpr.2016.03.009.

36. Parsons CE, Crane C, Parsons LJ, Fjorback LO, Kuyken W. Home practice in Mindfulness-Based Cognitive Therapy and Mindfulness-Based Stress Reduction: A systematic review and meta-analysis of participants' mindfulness practice and its association with outcomes. Behav Res Ther. 2017;95:29-41. doi: 10.1016/j.brat.2017.05.004. 